\title{
You'll Be Surprised - Digital Business Strategy as Driver of Organizational Innovativeness
}

\begin{abstract}
The presence of digital infrastructures fundamentally changes market conditions, business and IT strategy, and consequently organizational structures. This research investigates how the concept of a digital business strategy leads to increased organizational innovativeness and firm performance. We demonstrate how IT capabilities contribute to organizational innovativeness and induce the CIO's positive role for IT-enabled business innovation. By means of an online survey among 228 IT decision makers in knowledge-intensive industries in the U.S., the results reveal organizational innovativeness being significantly higher influenced by the IT knowledge of business employees in organizations giving the digital business strategy high importance, whereas the top management team IT knowledge plays a greater role when digital business strategy is given low priority. By this research, we deliver first results of consequences for organizations conducting a digital business strategy and contribute to the discussion on ITenabled innovation, CIO leadership, and the increasing relevance of organization-wide IT capabilities.
\end{abstract}

\section{Introduction}

For more than nearly four decades now the question whether or not technology is able to generate new products is discussed [26]. Today, highly digitized markets demand organizations to become more and more innovative [16], since the commonly used digital infrastructure is not enough to stay competitive, as it can be swiftly copied or imitated [7, 13, 46]. The emergence of digital infrastructures lowered market entrance barriers for new competitors and made switching easier for customers [34]. One way for organizations how to deal with these digitization challenges is by developing a digital business strategy (DBS) that merges business and information technology (IT) strategies [7] into a single one. A DBS allows organizations to generate more business value from IT and thereby more profit in highly competitive markets $[24,45]$. In order to implement a DBS successfully, a continuous and organization-wide culture towards innovativeness needs to be established [55].

Organizational innovativeness expresses the capability of an organization to generate innovations from the interplay between technical and administrative innovations [20]. As especially IT contributes to understand, synthesize, and apply technical knowledge for developing innovations [23], this research concentrates on the role of the CIO as agenda setter, influencer, and distributer of IT knowledge within organizations [31]. Especially in service and knowledge intense industries, IT knowledge is a pivotal organizational resource $[6,30,32,48]$ and becomes increasingly evident for the business-side due to forced business process digitization [13, 52]. Innovative organizations are also characterized by leadership balancing influences from "outside" with capabilities and knowledge from "inside" to assess potential innovation opportunities [27]. Here again the role of the CIO is mission critical as he or she is in charge of turning IT capabilities into IT-enabled business innovation [39].

This research aims for explaining the role of the CIO in more detail by focusing on how the distribution of IT knowledge to the business-side leads to organizational innovativeness which ultimately leads to organizational performance. We also exploratively look into how different degrees of executed DBS lead to different organizational innovativeness outcomes, which will reveal first insights on organizational consequences of DBS. Thus, we are answering the following research questions:

RQ1: How does CIO leadership influence business side's IT knowledge on managerial and employee level in firms executing a higher and lower degree of DBS?

RQ2: How does business side's IT knowledge on managerial and employee level influence organizational innovativeness in firms executing a higher and lower degree of DBS?

RQ3: How does organizational innovativeness influence firm performance in firms executing a higher and lower degree of DBS?

The remainder of the article is organized as follows: first, the theoretical background of the investigated concepts such as DBS, organizational innovativeness, and organizational knowledge are further highlighted. After developing the underpinning hy- 
potheses, we test the succeeding research model by means of a multi-group analysis in structural equation modeling based on the results of an online survey among 228 IT decision makers in knowledgeintensive organizations in the U.S. Finally, we discuss the results and limitation and give advice for future research.

\section{Literature Background}

\subsection{Digital Business Strategy}

A business strategy represents an organization's theme which determines how to differentiate from competitors and gain value in a chosen market $[18$, 33]. Business strategies function as pivotal medium between market and organization in constituting and triggering intrafirm operational planning and execution (internal) in order to achieve the placed market goals (external) [18]. The concept of DBS was first introduced by Mithas and Lucas [28] and subsequently refined by Bharadwaj et al. [7]. The supplement „digital“ adds the idea of „leveraging digital resources to create differential value" [7, p.472] to the definition of a business strategy. This extended concept questions established considerations such as on IT alignment [7, 13]. Coincidently, it opens theoretical and practical opportunities to renew and overcome the perspective of IT as traditional business support and service deliverer [32] towards an inseparable and key component of business processes, business models, and business strategies.

The DBS concept can be specified along four themes [7]: scope, scale, speed, and source. Scope describes the portfolio of referring (digital) products and services and corresponding challenges for the entire business ecosystem [24, 54]. Scale encompasses network effects associated with DBS going along with increased connectivity by digital infrastructures [46], accessible for the organization, its external partners, as well as for the competitors. Consequentially, the speed of business activities accelerates since every market actor can easily access and imitate based on these infrastructural abilities [13, 33]. Thus, the source theme of DBS focusses on business value creation and consequences in transforming business models, supply and value chains $[24,29]$.

Due to the broad accessibility of IT infrastructure for every market participant (supplier, rival, consumer) $[34,46]$, operational advantages decrease quickly, and strategic positioning remains as the only way to institute a surplus to the customer in shape of additional value leading finally to firm profits $[24,33$,
45]. For the themes of scope, scale, speed, and source of DBS, the leadership functions become even more evident [5] for understanding the external competitive environment and transfer the resulting insights to internal application of non-imitable resources [18]. Considering the "digital" aspects of DBS, the research at hand investigates the leadership role of the highest IT representative in organizations, the CIO $[4,50]$, in highly digitized knowledge-intensive firms. Especially extant results on specifies of technical strategies provide a solid research background $[17,55]$.

\subsection{Organizational Innovativeness}

Mintzberg [27] described an innovative organization as heavily oriented to its environment, even characterizing the environment as "precedence" [27, p.217]. Thus, market-orientated firms which are open to observe their business environment as well as competitors enjoy above average competitive advantage $[20,22]$.

Organizational innovativeness expresses the openness of an organization to integrate, absorb, reveal, and create newness. Not surprisingly, innovativeness is closely related with organizational culture that stimulates learning, development, and participative decisions [22]. In particular, organizational innovativeness significantly influences firm performance in turbulent markets [20], where a technologycentered strategy acts as mediator between organizational innovativeness and firm performance [17]. In these highly digitized and competitive markets, organizational innovativeness is supposed to serve as organizational capability of a longer lasting character and of high difficulty to imitate, with expected positive effects on competitive advantage [16].

In this research, we investigate organizational innovativeness as a result of profound knowledge about IT, similar to the concept of IT-enabled innovation $[2,15,23]$, and consequently analyze the influence of IT knowledge on organizational innovativeness. Further, we contribute to the discussion on digital innovations, which concentrates on both IT as enabler for creating innovations as well as on technological aspects of digital or digitized products $[1,53,54]$.

\subsection{Organizational Knowledge}

Organizational knowledge describes the assemblage of collective understandings in an organization [47], which is instrumental to achieve competitive advantage by deploying organizational resources [6]. In organizations, knowledge is not only stored in documents, repositories, or databases [3], but can 
also be embodied in organizational norms, routines, and practices [47] such as organizational innovativeness. Knowledge exchange and combination leads to higher firm performance [12], whereas these practices are costly before they turn into successful products, processes, or services [27, 45]. Value creation of today's products derives primarily from the development and management of intangible intellectual resources [48].

Especially in knowledge-intensive industries, hierarchical exposed senior managers effectively lead in stimulating organizational learning for creating organizational knowledge [43], whereas learning corresponds to organizational knowledge internalization [30]. Leaders act as (informational) sources and (interpersonal) energizer for creating knowledge [27] and were proven to influence organizational knowledge creation based on individual as well as organizational learning [25, 30, 43]. In innovative organizations, the leadership function has to balance influences from "outside" in order to transfer it continuously to the "inside" to provide the organization with broad guidelines to leave enough room for the employees to act innovatively [27].

Knowledge, IT, and innovativeness are closely intertwined: IT represents a crucial component for organizational knowledge [3, 30] whereas knowledge plays a crucial part in innovation processes [23, 55]. Innovation requires to integrate heterogeneous knowledge resources from both external as well as internal sources to generate creative ideas, tasks, or procedures [53]. IT offers a basis to acquire, collect, and internalize data and information, thereby enhancing the analytical capability of an organization and contributing to build organizational knowledge [23]. Especially for complex and technical undertakings, digital platforms serve to understand, synthesize, and apply knowledge in innovations developing [14, 53]. Consequently, this research investigates IT knowledge as essential organizational resource to achieve IT-enabled organizational innovativeness, as the strategic relevance of IT knowledge was widely established [6, 30, 32, 48].

\section{Research Model and Operationalization}

\subsection{Hypotheses and Research Model}

According to the presented definition of a digital business strategy as medium between market and organization, this research concentrates on internal organizational consequences (IT leadership, IT knowledge) and how these can lead to more business value (organizational innovativeness, market-based performance). This exploratory research focusses in particular on how the regarded influences vary in accordance with the degree of established DBS. Based on theoretical considerations, we propose every hypothesis to perform higher in high priority DBS organizations, in order to validate these assumptions to gain first quantitative results about realized DBS.

Figure 1. Research Model

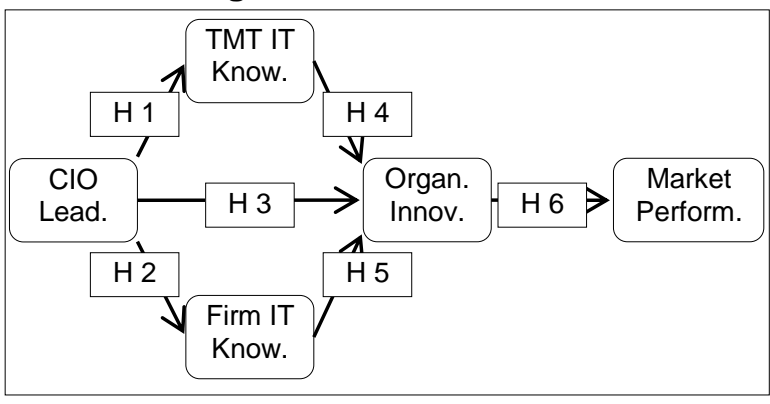

Hand in hand with the increasing relevance of IT within organizations, advanced non-technical competencies become equally important for fulfilling the CIO's function, in particular to develop IT-based opportunities for the business side [36]. As highest IT representative in an organization $[4,50]$, we consequently propose the CIO or its equivalent in an organization as knowledge leader in IT-related issues according to Mintzberg's leadership considerations $[27,50]$. In particular in knowledge-intensive industries, influential IT leadership establishes profound IT capabilities [8] and contributions of IT to firm efficiency and strategic growth [9]. As strategically innovation oriented firms are proven to utilize IS for shifting knowledge in their innovation cycle [14, 45], we propose:

H1: CIO leadership has a higher positive impact on TMT strategic IT knowledge in high-DBS organizations.

H2: CIO leadership has a higher positive impact on firm strategic IT knowledge in high-DBS organizations.

Overcoming the reduction of IT as mere business supporter, the CIO's role has also changed and expanded in enabling explorative IT capabilities and business innovations [4, 9]. The higher the involvement of the CIO in new product development, the higher the potential for IT-enabled business innovation [39]. While executing DBS has a positive effect on an organization's innovative ability [7], organizational leaders in particular have to provide "free space" in order to let innovation processes happen [27]:

H3: CIO leadership has a higher positive impact on organizational innovativeness in high-DBS organizations. 
IT-enabled intangibles such as IT capabilities have a positive impact on firm performance [6], whereas especially the IT knowledge of the TMT was proven to influence organizational success [36]. As IT capabilities lead to product innovativeness [10] and with firms in highly digitized markets being increasingly dependent on IT-enabled innovation [16], we hypothesize:

H4: TMT strategic IT knowledge has a higher positive impact on organizational innovativeness in high-DBS organizations.

We mindfully distinguish between IT knowledge on TMT and business employee level: While there is a lot of insights on how to build and what are the consequences of IT knowledge in the relation between the CIO and TMT in the context of social alignment [36], the CIO's influence on business employees IT knowledge has not discussed intensely IS research yet [51]. IT is an effective means to integrate and apply technical knowledge in developing innovation [23, 53], since applying organizational knowledge acts as basis for organizational innovativeness [55]. Since organizational knowledge can be embodied in norms, routines, and practices [47] with DBS intending to scale this organizational knowledge [7], we propose:

H5: Firm strategic IT knowledge has a higher positive impact on organizational innovativeness in high-DBS organizations.

Higher degrees of organizational innovativeness correspond with an increased number of successfully implemented innovations [22]. Technical and administrative innovations show a direct positive impact on firm performance [20], especially the number of (technical) innovations contribute to higher return on assets [44]. Since technology-oriented strategies mediate between organizational innovativeness and firm performance, we hypothesize:

H6: Organizational innovativeness has a higher positive impact on firm performance in high-DBS organizations.

\subsection{Operationalization of Constructs}

In order to test our hypotheses empirically, we conducted an online survey in 2016 among IT decision makers. All relevant measures were adopted or based on constructs from the AIS senior scholar basket journal publications or reviewed international IS conferences (table 1).

\section{Table 1. Measurement Items}

All measured on 5-point Likert scale: $1=$ not well informed, 5 = extremely well informed

\section{CIO Leadership [50]}

Providing new business-side employees with adequate training for the introduction to the IT related job tasks at hand.

Evaluating the quality of business-side employees' IT performance.

Gathering information about IT trends outside your organization.

Allocating IT equipment or related materials.

Learning about new ideas originating outside of your department.

TMT IT Knowledge [36]

How knowledgeable is the TMT of your company about the potential and limitations of current IT?

How knowledgeable is the TMT of your company about the potential and the limitations of "nextgeneration" IT?

How knowledgeable is the TMT of your company about how your competitors are applying IT?

Firm IT Knowledge ([51]; modified from [36]; originally: TMT IT knowledge)

How knowledgeable are the employees of your company about the potential and limitations of current IT?

How knowledgeable are the employees of your company about the potential and the limitations of "next-generation" IT?

How knowledgeable are the employees of your company about how your competitors are applying IT?

Organizational Innovativeness [49]

My organization readily accepts innovations based on research results.

Management in my organization actively seeks innovative ideas.

Innovation is readily accepted in this organization.

People are penalized for new ideas that don't work. (Reverse coded)

Innovation in this organization is perceived as too risky and is resisted. (Reverse coded)

Firm Performance: Market Based Firm Performance [37]

We have entered new markets very quickly.

We have brought new products and services to the market faster than our competitors.

The success rates of our new products and services have been very high

For CIO leadership, we use items of a recent study that comprises contemporary, IT specialized, and modernized IT managerial roles based on Mintzberg's theoretical concepts [50]. The items capture the relevance of IT supply to the business side in terms of IT skills training and evaluating business IT 
performance, as assumed predecessor for IT knowledge. Furthermore, allocating IT resources plays a critical role as well. Lastly, the items reflect gathering external information as well as gathering information from the business-side to demonstrate the leadership function in arranging for acquiring new organizational IT knowledge.

The item set for TMT strategic IT knowledge was adopted from a well-recognized analysis on social alignment between CIO and TMT which is suitable to measure the impact of knowledge on organizational phenomena on senior level [36]. The scale covers TMT knowledge on current and future IT as well as market-oriented IT knowledge, emphasizing knowledge about IT applied by competitors. For firm strategic IT knowledge, the instrument was taken from a recent research in the field of IT alignment [51], adopting the aforementioned scale of Preston and Karahanna [36]. Whereas IT capabilities have commonly been regarded as restricted to the routines of the IT department [37], current research has proven the demand for expanding the concept to the whole organization due to the increasing capacity of IT for business processes [52]. The research at hand concentrates on the relevant predecessor for IT capabilities [32], IT knowledge, to take account of this essential organization-wide resource of the businessside.

Expressing organizational innovativeness as one facet of organizational culture, the measures were adopted from [22] represented by five items having readily been utilized in the context of IS [49]. Market-based performance was conceptualized applying a three-item construct applied for measuring firm performance in the original source. It was adopted from a study with a similar innovation-centered context, namely investigating the influence of IT resources and capabilities on firm performance especially for firms entering new markets and launching new products successfully during the past three years [37].

\section{Data Collection and Research Analysis}

\subsection{Data Preparation and Survey Sample}

In order to test the proposed hypotheses, a study sample of 228 senior IT decision makers in the U.S. was collected within a quantitative, questionnaire based online survey. 1,015 participants of a CIO panel operated by a large international market research institute were invited between December 2016 and January 2017 to answer the survey. In particular, we focused on knowledge-intensive organizations, as classified by the OECD [31] to concentrate on firms who are most likely to have a DBS (table 2).

In addition to control for industry sector, we ensured for firm sizes larger than 50 employees and IT departments with more than two employees. Several plausibility checks were implemented within the online questionnaire to enhance data quality in advance and items were arranged randomly to avoid order bias. A secondary data quality procedure based on an analysis of three track questions and the plausibility of given demographics excluded 49 further respondents. Measured based on the established scale of Sharma and Rai [42], we recognize a high degree of senior IT decision makers among the respondents, whereas the tracked CEOs additionally act as CIOs at the same time (table 2). The average CIO within the sample is 43.9 years old, is in $64 \%$ of the cases male, has IT experience of 14.8 years and an organizational tenure of 12.4 years. Analyzing firm characteristics, the average firm in our sample was founded in 1975, has 28,557 employees, and an IT department supported by 5,016 IT employees (table 3). Summing up, the sample provides a well dispersed view on CIOs in knowledge-intensive industries in the U.S. in order to evaluate the presence of DBS and organizational innovativeness.

\begin{tabular}{|c|c|c|c|c|c|}
\hline \multicolumn{6}{|c|}{ Table 2. Full Sample Characteristics } \\
\hline \multicolumn{2}{|c|}{ Gender } & \multicolumn{4}{|c|}{ Age } \\
\hline Male & Female & $26-35$ & 54 & $56-65$ & 31 \\
\hline 147 & 81 & $36-45$ & 79 & $66-75$ & 7 \\
\hline $64 \%$ & $36 \%$ & $46-55$ & 56 & $76-85$ & 1 \\
\hline \multicolumn{6}{|c|}{ Job Position } \\
\hline \multicolumn{4}{|c|}{ CEO, Sr V.P., V.P. } & 53 & $23.2 \%$ \\
\hline \multicolumn{4}{|c|}{$\begin{array}{l}\mathrm{CIO} / \text { vice president of IT, chief } \\
\text { technology officer, chief security } \\
\text { officer }\end{array}$} & 68 & $29.8 \%$ \\
\hline \multicolumn{4}{|c|}{$\begin{array}{l}\text { director of systems development, } \\
\text { director of IT/IS operations, internet } \\
\text { technology strategist }\end{array}$} & 76 & $25.0 \%$ \\
\hline \multicolumn{4}{|c|}{ other IT decision makers } & 31 & $35.2 \%$ \\
\hline \multicolumn{6}{|c|}{ Knowledge-intensive Industry Sector $(n>10)$} \\
\hline \multicolumn{5}{|c|}{ Computer (Hardware, Software, Services) } & 48 \\
\hline \multicolumn{5}{|c|}{ Education, Training } & 43 \\
\hline \multicolumn{5}{|c|}{ Banking, Financial Services, Insurance } & 30 \\
\hline \multicolumn{5}{|c|}{ Industrial Manufacturing } & 28 \\
\hline \multicolumn{5}{|c|}{ Healthcare, Medical, Pharmaceutics } & 25 \\
\hline \multicolumn{5}{|c|}{ Aerospace, Automotive, Defense } & 12 \\
\hline \multicolumn{5}{|c|}{ Advertising, Consulting, Market Research } & 12 \\
\hline \multicolumn{5}{|c|}{ Other } & 30 \\
\hline
\end{tabular}

To differentiate the degree of executed DBS within the knowledge-intensive organizations, we asked the respondents to indicate how much this statement applies to their organization (rated on a 5-point Likert 
scale): "Our organizational strategy is formulated and executed by leveraging digital resources to create differential value", adopted from the given DBS definition (7, p. 472). A discriminance analysis conducted by means of IBM SPSS Statistics software Version 21 led to a group division resulting in low-DBS ( $n=98$, for lower Likert values) as well as high-DBS organizations ( $n=130$, higher Likert values).

The comparison of the two groups shows several relevant and significant deviations for descriptive variables (table 3): mainly, high-DBS firms are significantly larger than low-DBS companies. Likewise, market share and IT department size correlate with firm size and show higher values for high-DBS. Even considering these effects, the calculated relation of firm size towards IT department size results in a significantly higher IT employee intensity in high-DBS firms, resulting in 8.5 employees ministered by one IT employee in high-DBS firms towards 10.2 in lowDBS firms. IT experience and organizational tenure of a CIO is slightly higher in high-DBS firms (about one year), but the difference is not significant. For the entire sample, the average firm was founded in 1975 equally for both groups, independent from DBS.

\begin{tabular}{|c||c|c|c|c|}
\hline \multicolumn{5}{|c|}{ Table 3. Differences Group Characteristics } \\
\hline $\begin{array}{c}\text { Means of } \\
\text { groups }\end{array}$ & $\begin{array}{c}\text { Firm } \\
\text { Size }\end{array}$ & $\begin{array}{c}\text { Market } \\
\text { Share }\end{array}$ & $\begin{array}{c}\text { Size IT } \\
\text { Unit }\end{array}$ & $\begin{array}{c}\text { F.Size/ } \\
\text { IT Unit }\end{array}$ \\
\hline Low-DBS & 3,166 & 35 & 149 & 10.2 \\
\hline High-DBS & 47,698 & 46 & 8,684 & 8.5 \\
\hline Full Sample & 28,557 & 41 & 5,016 & 9.2 \\
\hline
\end{tabular}

\subsection{Measurement Model Validation}

To test the proposed hypotheses, we computed the research model within a structural equation modeling (SEM) by means of SmartPLS v.3.2.3 [38]. Prior to analyzing the path differences dependent on the DBS groups, the quality criteria show very good properties for the reflective measurement constructs (table 4): for construct reliability, Cronbach's alpha revealed for all constructs values over the desirable Nounally minimum of 0.7 (0.835 and higher), for construct validity the average variance extracted (AVE) lied between 0.6 and 0.85 , which is explicitly higher than the postulated threshold of 0.5 [11], and composite reliability (CR) between 0.883 and 0.946 . For discriminant validity, we found the Fornell and Larcker criterion as achieved by identifying the AVE of each construct as higher than the square root of the correlation to every other construct. The $\mathrm{R}^{2}$ values of all dependent constructs indicate strong amount of explained variance [11].
For a deeper understanding of the influence of implemented DBS for the interesting hypotheses, we conducted a group comparison between high-DBS and low-DBS organizations. The rationale for conducting a group comparison is caused in the huge heterogeneity between at least two groups of respondents, resulting in significantly differing model relationships [19]. In this analysis, we applied the PLS multigroup analysis (MGA) [21] to test for proposed path deviations between these groups. Following the computation approach provided in SmartPLS 3 [38], we conducted a multigroup bootstrapping based on 5,000 subsamples and a two-tailed bootstrapping test type on a significance level of 0.05 [40].

\begin{tabular}{|c|c|c|c|c|}
\hline \multicolumn{6}{|c|}{ Table 4. Reliability, Validity, Determination } \\
\hline Construct & AVE & CR & Alpha & $\mathbf{R}^{\mathbf{2}}$ \\
\hline $\begin{array}{c}\text { CIO } \\
\text { Leadership }\end{array}$ & 0.602 & 0.883 & 0.835 & - \\
\hline $\begin{array}{c}\text { TMT IT } \\
\text { Knowledge }\end{array}$ & 0.853 & 0.946 & 0.914 & 0.342 \\
\hline $\begin{array}{c}\text { Firm IT } \\
\text { Knowledge }\end{array}$ & 0.822 & 0.933 & 0.892 & 0.270 \\
\hline $\begin{array}{c}\text { Organizational } \\
\text { Innovativeness }\end{array}$ & 0.757 & 0.903 & 0.840 & 0.554 \\
\hline $\begin{array}{c}\text { Market Based } \\
\text { Performance }\end{array}$ & 0.822 & 0.933 & 0.891 & 0.525 \\
\hline $\begin{array}{c}\text { AVE = Average Variance Extracted, Alpha = Cronbach's } \\
\text { alpha, CR = Composite Reliability, R }\end{array}$ C.of determination \\
\hline
\end{tabular}

All in all, five of the six hypotheses show interesting results within the MGA: three multigroup differences are significant (figure 2), two show stable performance in both samples meaning throughout the whole sample, and one difference is not significant but shows a clear tendency. All path coefficients in the subsamples are significant on 5\% level or higher, mostly on 0.01 level, which allows for interpreting both the differences and the segregated values. Only the path difference from firm IT knowledge on organizational innovativeness is not significant due to its value of nearby zero in the low-DBS group, which, however, is a relevant finding and will be discussed in detail in the results section.

First, we find significantly higher influence of a CIO's leadership activities on IT knowledge in highDBS firms (H1, H2), on both TMT and firm IT knowledge. This confirms prior findings on how the CIO influences IT knowledge throughout the whole organization $[8,36,52]$ and underlines the exceptional role of IT knowledge on all hierarchical levels in knowledge intensive industries. Further, we state the CIO's leadership function as playing a more crucial role especially in high-DBS organizations. 


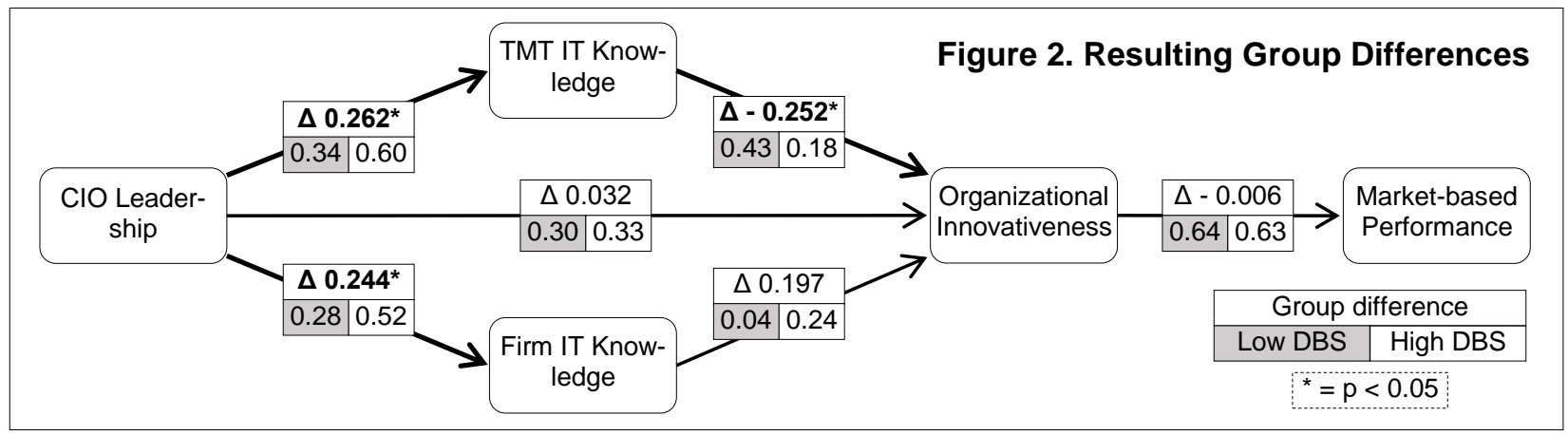

Second, we state a significantly lower impact of TMT's IT knowledge on organizational innovativeness in high-DBS firms, but remaining on lower level of 0.181 in low-DBS companies (rejection of H4). This reduced effect for high-DBS organizations is particularly interesting, whereas the influence of firm IT knowledge on organizational innovativeness increases in parallel (confirming H5). Notably, the latter effect is exclusively found for high-DBS firms, as nearly any influence could be found from firm IT knowledge on organizational innovativeness in lowDBS firms (0.049). The identified group difference for $\mathrm{H} 5$ shows an error probability of $\mathrm{p}=0.094$, which is quite good, but not sufficient for the recommended significance of 5\% for MGA [40]. We take this statistical inaccuracy as a minor issue, as these opposing effects of $\mathrm{H} 4$ and $\mathrm{H} 5$ on organizational innovativeness are reasonable and verify DBS as a faster and more performance-oriented business strategy by integrating employees' IT knowledge.

Further, the direct influence of the CIO on organizational innovativeness stays nearly equal in both sub-samples, proved by an insignificant path difference of 0.032 only (rejection of H3). Finally, the influence of organizational innovativeness on marketbased performance was found similar for the whole sample as well (rejection of H6), underlining the general importance of this organizational ability on firm performance in knowledge-intensive businesses.

Calculated using a components based approach with a 500 sample bootstrapping technique, the results for the complete sample (figure 3 ) show highly significant paths $(p<0.01)$ for all hypotheses, except for the connection from firm IT knowledge on organizational innovativeness significant at $\mathrm{p}=0.04$. We find three large effects from CIO leadership on both TMT and firm IT knowledge as well as from organizational innovativeness on market based performance. These significances statistically support the main findings of the conducted MGA. In accordance with the prescribed procedures $[19,35]$, we conducted a mediation analysis of all possible additional connections going beyond the disposed hypotheses. Hence, we found weak direct input from both TMT and firm IT knowledge on market based performance, since the influence is significantly lower than the hypothesized findings, we regard this as minor issue. Further, CIO leadership shows direct influence on market based performance as well (0.255), which supposes organizational innovativeness not to be the only aspect in which IT leaders affect firm performance. As this for example corresponds with extant findings in literature on IT alignment or leadership influenced organizational cultures, we regard this effect as reasonable and supporting our results.

\section{Figure 3. Structural Model Full Sample}

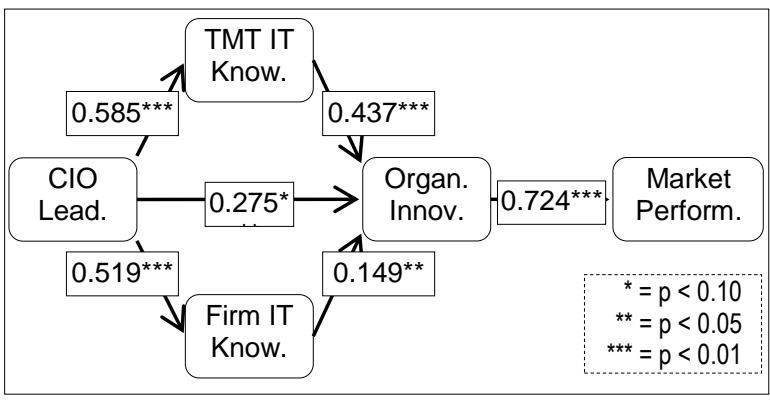

\section{Results and Discussion}

This research conducted a group comparison of organizations executing either DBS at high or low level based on data gained from 228 IT decision makers in the U.S. Particularly, this analysis investigates differences in the influence of the CIO on IT knowledge in these organizations, the relevance of IT knowledge for organizational innovativeness, and finally on firm performance.

Generally, we can underline the costly and - at first glance - inefficient processes of sharing and creating organizational knowledge as relevant to provide organizations to cope with the challenges arising in highly digitized markets by means of organizational innovativeness [27]. Especially organizations conducting a DBS take advantage of the pivotal resource 
of IT knowledge on the managerial and the business employee level. We primarily want to highlight that the positive consequences of firm IT knowledge exclusively occur in organizations executing DBS to achieve organizational innovativeness. This supposes that the type of strategy an organization conducts significantly impacts how organizational knowledge is utilized for organizational innovativeness, resulting to increased firm performance in the same step. Based on a sample of industries grouped upon the degree of knowledge intensity provided by the OECD [31], we are able to confirm recent considerations on organizations becoming increasingly dependent on IT based innovations [16].

To our knowledge, the research at hand is the first in the field of IS to prove evidence how the implementation of DBS positively influences organizational innovativeness and thereby firm performance. This is due to the innovation-centered aspects of the DBS concept [7]. We further were able to validate and extend prior findings supposing that technologyoriented strategies contribute to organizational innovativeness [55] and firm performance as a consequence [17]. Especially for the analyzed case of DBS, we can empirically confirm the high interweaving of business strategy and innovation in knowledge-intensive industries [45]. This research found convincing empirical evidence how knowledge-intensive organizations transfer external influences by means of an IT-related business strategy, namely DBS, to effective internal organizational structures and resources, as recommended for market oriented organizations [27]. This is particularly essential for competitive reasons since the capability of organizational innovativeness is even harder to imitate as part of organizational culture [15, 22, 23]. We present how the challenges of highly digitized and competitive markets result in a yet started fundamental change of traditional internal structures, organizational resources and capabilities, and strategy concepts, as supposed by [7, 13, 16, 46].

In more detail, we found strong evidence for two general relationships on basis of the complete sample: first, the influence of organizational innovativeness on market performance performs similar in both subsamples (H6) as it has been stated already in prior research [17, 20, 44]. This emphasizes the relevance of business strategies to transfer innovations effectively to the market in general [18]. Further, the influence of the $\mathrm{CIO}$ on organizational innovativeness performs nearly equally for both groups (H3), underlining the pivotal influence of the CIO's potential for IT-enabled business innovation [39].

For the entire sample, we can state a hierarchically similar influence of the CIO on IT knowledge of the TMT or of business employees $(\mathrm{H} 1, \mathrm{H} 2)$. Differing between the two DBS groups, we find a significantly higher influence of CIO leadership on both types of IT knowledge $(\mathrm{H} 1, \mathrm{H} 2)$, underlining by empirical results that both IT knowledge and CIO leadership plays a more present role in DBS organizations [7] as well as CIO leadership in influencing it [5]. Regarding the whole sample, the impact of the TMT IT knowledge on organizational innovativeness seems to be higher than of business employees' at first sight, whereas the multigroup results reveal a differentiated perspective: The high influence of TMT IT knowledge is mainly true to low-DBS organizations, forasmuch as it decreases to a lower level in high-DBS firms (rejection of H4). This particularly is important as the influence of firm IT knowledge increases in organizations conducting a DBS (H5). We can state that high-DBS organizations more intensively take advantage of the improvements offered by utilize IT and IT capabilities for innovation processes [10, 45, 53], IT-enabled innovation seems to be more established in DBS oriented organizations. Furthermore, we can concretize prior findings on how the hierarchical level distinguishes in being affected by knowledge processes [41].

For IT leaders in practice, our findings reassure and intensify the CIO to utilize IT for business innovation [9]. We applied a modernized comprehensive IT leadership construct [50], underlining the CIO's function as crucial institution in executing a (digital) business strategy as mediator between the external environment and internal structures and resources, since the used items express gathering information from outside of the organization as well as ideas from the business-side for acquiring new organizational knowledge as part of the IT leadership role. Our findings further confirm the influence of organizational leaders on knowledge creation and dissemination as extant literature supposes [30, 43]. Organization executing DBS generate organizational innovativeness by integrating more firm IT knowledge than TMT IT knowledge, compared to less DBS organizations. In practice, CIOs in high digitized business environments shall concentrate on reinforcing this employee level based organizational resource.

For future research, the CIO function needs to be further analyzed to determine how the increased influence of the CIO on IT knowledge on both regarded levels signifies a higher influence of CIO in strategic questions on managerial level, as organizational leaders generally are in charge of strategy setting [18]. For the CIO's influence on firm IT knowledge, the mediating effect of TMT IT knowledge should be investigated in advance [51]. For themes about innovation, IT-related organizational structures could be 
introduced into the discussion such as the (de)centralization of IT [44].

\section{References}

[1] Abrell, T., M. Pihlajamaa, L. Kanto, J. Vom Brocke, and F. Uebernickel, "The role of users and customers in digital innovation: Insights from B2B manufacturing firms", Information \& Management, 53(3), 2016, pp. 324-335.

[2] Agarwal, R. and V. Sambamurthy, "Principles and Models for Organizing the IT Function", MIS Quarterly Executive, 1(1), 2002, 1-16.

[3] Alavi, M. and D.E. Leidner, "Review: Knowledge Management and Knowledge Management Systems: Conceptual Foundations and Research Issues", MIS Quarterly, 25(1), 2001, pp. 107-136.

[4] Banker, R.D., N. Hu, P.A. Pavlou, and J. Luftman, "CIO Reporting Structure, Strategic Positioning, and Firm Performance", MIS Quarterly, 35(2), 2011, pp. 487-504.

[5] Bennis, W., "Leadership In A Digital World: Embracing Transparency And Adaptive Capacity", MIS Quarterly, 37(2), 2013, pp. 635-636.

[6] Bharadwaj, A.S., "A Resource-Based Perspective on Information Technology Capability and Firm Performance: An Empirical Investigation", MIS Quarterly, 24(1), 2000, pp. 169-196.

[7] Bharadwaj, A.S., O.A. El Sawy, P.A. Pavlou, and N.V. Venkatraman, "Digital business strategy: toward a next generation of insights", MIS Quarterly, 37(2), 2013, pp. 471-482.

[8] Chatterjeem, D., V.J. Richardson, and R.W. Zmud, "Examining the Shareholder Wealth Effects of Announcements of Newly Created CIO Positions", MIS Quarterly, 25(1), 2001, pp. 43-70.

[9] Chen, D.Q., D.S. Preston, and W. Xia, "Antecedents and Effects of CIO Supply-Side and DemandSide Leadership: A Staged Maturity Model", Journal of Management Information Systems, 27(1), 2010, pp. 231-272.

[10] Chen, Y., Y. Wang, S. Nevo, J. Benitez-Amado, and G. Kou, "IT capabilities and product innovation performance: The roles of corporate entrepreneurship and competitive intensity", Information \& Management, 52(6), 2015, pp. 643-657.

[11] Chin, W.W., The Partial Least Square Approach to Structural Equation Modeling, Lawrence Erlbaum Associates, Mahwah, New Jersey, USA, 1998.

[12] Collins, C.J. and K.G. Smith, "Knowledge Exchange and Combination: The Role of Human Resource Practices in the Performance of High Technology Firms", Academy of Management Journal, 49(3), 2006, pp. 544-560.

[13] Coltman, T., P. Tallon, R. Sharma, and M. Queiroz, "Strategic IT alignment: Twenty-five years on",
Journal of Information Technology, 30(2), 2015, pp. 91-100.

[14] Dougherty, D. and D.D. Dunne, "Digital Science and Knowledge Boundaries in Complex Innovation", Organization Science, 23(5), 2012, pp. 1467-1484.

[15] Fichman, R.G., "The Role of Aggregation in the Measurement of IT-Related Organizational Innovation", MIS Quarterly, 25(4), 2001, pp. 427-455.

[16] Fichman, R.G., B.L. Dos Santos, and Z.E. Zheng, "Digital Innovation as a fundamental and powerful Concept in the Information Systems Curriculum", MIS Quarterly, 38(2), 2014, pp. 329-353.

[17] Gatian, A.W., R.M. Brown, and J.O. Hicks, JR., "Organizational innovativeness, competitive strategy and investment success", Journal of Strategic Information Systems, 4(1), 1995, pp. 43-59.

[18] Grant, R.M., Contemporary Strategy Analysis, 7th edn., Wiley, West Sussex, UK, 2010.

[19] Hair, J.F., A primer on partial least squares structural equations modeling (PLS-SEM), SAGE, Los Angeles, USA, 2014.

[20] Han, J.K., N. Kim, and R.K. Srivastava, "Market Orientation and Organizational Performance: Is Innovation a Missing Link?", Journal of Marketing, 62(4), 1998, pp. 30-45.

[21] Henseler, J., C.M. Ringle, and R.R. Sinkovics, Advances in International Marketing, Emerald Group Publishing, Bingley, 2009.

[22] Hurley, R.F. and G.T. Hult, "Innovation, Market Orientation, and Organizational Learning: An Integration and Empirical Examination", Journal of Marketing, 62(3), 1998, pp. 42-54.

[23] Joshi, K.D., L. Chi, A. Datta, and S. Han, "Changing the Competitive Landscape: Continuous Innovation Through IT-Enabled Knowledge Capabilities", Information Systems Research, 21(3), 2010, pp. 472-495.

[24] Keen, P. and R. Williams, "Value Architectures For Digital Business: Beyond The Business Model", MIS Quarterly, 37(2), 2013, pp. 643-647.

[25] Krogh, G. von, I. Nonaka, and L. Rechsteiner, "Leadership in Organizational Knowledge Creation: A Review and Framework", Journal of Management Studies, 49(1), 2012, pp. 240-277.

[26] McFarlan, F.W., "Portfolio approach to information-systems", Harvard Business Review, 59(5), 1981, pp. 142-150.

[27] Mintzberg, H., Mintzberg on management: Inside our strange world of organizations, Simon and Schuster, New York, USA, 1989.

[28] Mithas, S. and H.C. Lucas, "What is Your Digital Business Strategy?", IT Professional, 12(6), 2010, pp. 4-6.

[29] Mithas, S., A.R. Tafti, I. Bardhan, and J.M. Goh, "Information technology and firm profitability: 
mechanisms and empirical evidence", MIS Quarterly, 36(1), 2012, pp. 205-224.

[30] Nonaka, I., "A Dynamic Theory of Organizational Knowledge Creation", Organization Science, 5(1), 1994, pp. 14-37.

[31] OECD, OECD Science, Technology and Industry Scoreboard 2013, Organization for Economic Cooperation \& Development, Paris, France, Washington, USA, 2013.

[32] Peppard, J. and J. Ward, "Beyond strategic information systems: Towards an IS capability", The Journal of Strategic Information Systems, 13(2), 2004, pp. 167-194.

[33] Porter, M.E., "What is Strategy?", Harvard Business Review, 74(6), 1996, pp. 51-54.

[34] Porter, M.E., "Strategy and the Internet", Harvard Business Review, 79(3), 2001, pp. 62-78.

[35] Preacher, K.J. and A.F. Hayes, "Asymptotic and resampling strategies for assessing and comparing indirect effects in multiple mediator models", Behavior Research Methods, 40(3), 2008, pp. 879-891.

[36] Preston, D.S. and E. Karahanna, "Antecedents of IS Strategic Alignment: A Nomological Network", Information Systems Research, 20(2), 2009, pp. 159179.

[37] Ravichandran, T. and C. Lertwongsatten, "Effect of Information Systems Resources and Capabilities on Firm Performance: A Resource-Based Perspective", Journal of Management Information Systems, 21(4), 2005, pp. 237-276.

[38] Ringle, C.M., S. Wende, and J.-M. Becker, "SmartPLS 3.2.6", SmartPLS GmbH, Boenningstedt, Germany, 2016.

[39] Saldanha, T. and M. Krishnan, "Leveraging IT for Business Innovation: Does the Role of the CIO Matter?", 32nd International Conference on Information Systems (ICIS 2011), Shanghai, China, 2011.

[40] Sarstedt, M., J. Henseler, and C.M. Ringle, "Multigroup Analysis in Partial Least Squares (PLS) Path Modeling: Alternative Methods and Empirical Results", in Measurement and Research Methods in International Marketing, M. Sarstedt, M. Schwaiger, and C.R. Taylor, Editors. 2011. Emerald Group Publishing Limited.

[41] Schulz, M., "The Uncertain Relevance of Newness: Organizational Learning and Knowledge Flows", Academy of Management Review, 44(4), 2001, pp. 661-681.

[42] Sharma, S. and A. Rai, "Adopting IS process innovations in organizations: The role of IS leaders' individual factors and technology perceptions in decision making", European Journal of Information Systems, 24(1), 2015, pp. 23-37.

[43] Škerlavaj, M., V. Dimovski, and K.C. Desouza, "Patterns and structures of intra-organizational learn- ing networks within a knowledge-intensive organization", Journal of Information Technology, 25(2), 2010, pp. 189-204.

[44] Subramanian, A. and S. Nilakanta, "Organizational Innovativeness: Exploring the Relationship Between Organizational Determinants of Innovation, Types of Innovations, and Measures of Organizational Performance", Omega, 24(6), 1996, pp. 631-647.

[45] Teece, D.J., "Business Models, Business Strategy and Innovation", Long Range Planning, 43(2-3), 2010, pp. 172-194.

[46] Tilson, D., K. Lyytinen, and C. Sørensen, "Research Commentary -Digital Infrastructures: The Missing IS Research Agenda", Information Systems Research, 21(4), 2010, pp. 748-759.

[47] Tsoukas, H. and E. Vladimirou, "What is Organizational Knowledge?", Journal of Management Studies, 38(7), 2001, pp. 973-993.

[48] Van de Ven, A.H., "Running in Packs to Develop Knowledge-Intensive Technologies", MIS Quarterly, 29(2), 2005, pp. 365-377.

[49] Venkatesh, V. and H. Bala, "Adoption and Impacts of Interorganizational Business Process Standards: Role of Partnering Synergy", Information Systems Research, 23(4), 2012, pp. 1131-1157.

[50] Wunderlich, N. and R. Beck, "25 Years of CIO and IT Leadership - Revisiting Managerial Roles in Information Systems Research", Proceedings of the 21st Pacific Asia Conference on Information Systems (PACIS 2017); Langkawi, Malaysia, 2017.

[51] Wunderlich, N. and R. Beck, "Time for Climate Change: Leadership, IT Climate, and their Impact on Organizational Performance", Proceedings of the 50th Hawaii International Conference on System Sciences (HICSS 2017); Big Island, Hawaii, USA, 2017, pp. 5037-5046.

[52] Wunderlich, N. and R. Beck, "We've Got the Power - The Relevance of IT Leadership and Organizational IT Capabilities in the Fully Digitized Business Era", Proceedings of the 25th European Conference on Information Systems (ECIS 2017); Guimaraes, Portugal, 2017.

[53] Yoo, Y., R.J. Boland, K. Lyytinen, and A. Majchrzak, "Organizing for Innovation in the Digitized World", Organization Science, 23(5), 2012, pp. 1398-1408.

[54] Yoo, Y., O. Henfridsson, and K. Lyytinen, "Research Commentary - The New Organizing Logic of Digital Innovation: An Agenda for Information Systems Research", Information Systems Research, 21(4), 2010, pp. 724-735.

[55] Yu, Y., X.-Y. Dong, K.N. Shen, M. Khalifa, and J.-X. Hao, "Strategies, technologies, and organizational learning for developing organizational innova- 
tiveness in emerging economies", Journal of Business

Research, 66(12), 2013, pp. 2507-2514. 